\title{
Study of the behaviour of diamond saw-blades in stone processing
}

\author{
S.Y. Luo ${ }^{\mathrm{a}, *}$, Y.S. Liao ${ }^{\mathrm{b}}$ \\ aepartment of Mechanical Engineeriny, Huafan College of Humanities and Technology, \\ Taipei, Taiwan, $R O C$ \\ ${ }^{6}$ Department of Mechanical Engineering, National Taiwan University, Taipei, Taiwan, ROC
}

Received 10 December 1993

\section{Industrial Summary}

The conditions of the diamond on the working surface of the tools in sawing Indian red granite using diamond saw-blades have been studied in this paper, and the effects of the types and the sizes of the diamond on the sawing performance of the saw-blades have been also investigated. SEM and toolmaker's microscope analyses of the diamond blades after sawing indicate that the conditions of the worn particles can be classified as follows: whole (without significant wear), polished (flat), micro-fractured, macro-fractured, and pull-out. Experimental results show that sawblades containing higher toughness grits result in a better blade performance, lower sawing forces, and a greater proportion of whole and pull-out grits occurring on the worn surface. When saw-blades containing smaller size grits of the same concentration are used, the blade performance is better, but the sawing forces are relatively larger, and a greater proportion of particle are pulled-out with a small number of polished grits appearing on the working segment surface.

\section{Introduction}

Circular diamond saw-blades designed for processing stones are made up of diamond grits, a bonding matrix, and a steel core to which the segments are attached. The grade of the diamond grits used in the segments is determined primarily by the stone to be cut, the sawing conditions, and the type of diamond tool. The size of the diamond particles influences the cutting rate, the surface finish of the workpiece and, to some extent, the life of the saw-blade.

In general, the diamond crystals must have sufficient strength to withstand the repeated cutting forces during the granite sawing process. If the diamond is too weak in strength, it will easily produce macro-cracks and crushed particles, and it will also cause the blade to act hard and possibly glazing will occur. Conversely, if the diamond has very high strength and toughness, it will be difficult to fracture to produce new

\footnotetext{
* Corresponding author.
} 
cutting points and edges. In addition, it will be polished to cause the blade to have a glazed appearance. The choice of the optimum diamond type for a given application depends on many factors, such as the stone type, the cutting conditions, the type and quality of the machine, etc.

Various studies have been conducted to investigate the effects of the diamond type and size on wear and sawability in the processing of stone with diamond saw-blades. Jennings and Wright [1] stated that hard materials usually require a smaller size diamond than do softer stones: this is because the load per particle is not sufficiently high, and a greater clearance is required for swarf. Conversely, if large diamond grits are used on hard materials, the penetration of the diamond is limited, and normally either excessive grit pull-out will occur or large wear flats will appear on the diamond particles. They also stated that the diamond of a blocky, regular shape with a predominance of cubo-octahedral crystals is the ideal shape for maximum strength and wear resistance and is suitable for the cutting of exceptionally hard materials or when high sawing rates are required.

In analyzing the cutting process and diamond wear, Büttner [2] found that if the diamond is too friable it will wear faster than the bond material and consequently it causes the blade to act hard and possibly glazing will occur. Contrarily, if the bond material is too soft, the diamond will be lost before completing its effective working life, leading to excessive tool costs. Thus, the bonding material must wear at the same rate as the diamond particle in order to facilitate constant efficient cutting.

Tönshoff and Warnecke [3] reported that in applying circular saw-blades, a medium grit size and a high concentration at high cutting rates, and a smaller grit size and a low concentration at low cutting rates, provided favourable cutting conditions as far as tool stability and economic operation are concerned.

Burgess [4] stated that the size of the diamond abrasive used in the segments is determined by the cutting speed and the type of finish required on the stone being cut. A good general rule is always to use the coarsest mesh size possible commensurate with the desired finish requirements. For most stone-working tools the diamond size used varies from 25 mesh to 100 mesh $(0.75-0.15 \mathrm{~mm}$ average crystal diameter).

Studies related to the wear characteristics and performance of the diamond sawblade in the sawing of stone have been reported by several investigators [5-10]. Nevertheless, the behaviour of a diamond saw-blade in the sawing of stone has not been understood thoroughly. In this paper, observations of the behaviour of diamond particles in the sawing of Indian red granite using an experimental one-segmented diamond saw-blade is presented. The effects of the grade and size of the diamond crystal on the blade wear and sawability are investigated also.

\section{Experimental procedures}

\subsection{Saw-blade specifications}

The diamond saw-blade used in the tests had a diameter of $205 \mathrm{~mm}$ and a steel core of thickness of $5 \mathrm{~mm}$. A diamond-impregnated segment (length $40 \mathrm{~mm}$ and width 


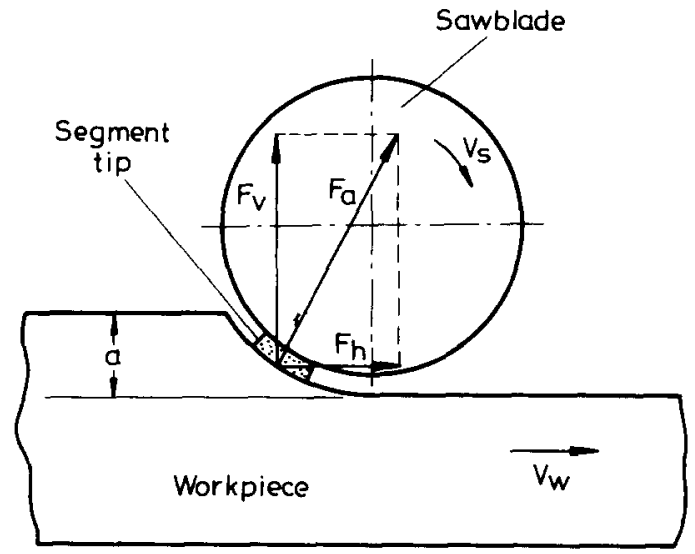

Fig. 1. Geometry of a one-segmented saw-blade.

Table 1

Description of the diamond segments in the sawblades

\begin{tabular}{lllll}
\hline $\begin{array}{l}\text { Sawblade } \\
\text { no. }\end{array}$ & $\begin{array}{l}\text { Type of } \\
\text { diamond }\end{array}$ & $\begin{array}{l}\text { Mesh size } \\
\text { of diamond }\end{array}$ & $\begin{array}{l}\text { Diamond } \\
\text { concentration }\end{array}$ & $\begin{array}{l}\text { Bond } \\
\text { composition }\end{array}$ \\
\hline A & MBS-70 & $40 / 50$ & 20 & $\mathrm{Co}-\mathrm{Cu} / \mathrm{Sn}$ \\
B & MBS-750 & $40 / 50$ & 20 & $\mathrm{Co}-\mathrm{Cu} / \mathrm{Sn}$ \\
$\mathrm{C}$ & MBS-750 & $40 / 50(50 \mathrm{wt} \%)$ & 20 & $\mathrm{Co}-\mathrm{Cu} / \mathrm{Sn}$ \\
\hline
\end{tabular}

${ }^{a}$ Trademark of General Electric Company, USA.

$7 \mathrm{~mm}$ ) was brazed to the periphery of a circular steel core (see Fig. 1). Sawing operations of the granite using the experimental one-segmented diamond blade were carried out for the evaluation of the sawing performance.

The specifications of the diamond segments for various saw-blades are given in Table 1. The abrasives used in the test were MBS- $70^{1}$ and MBS- $750^{1}$, a light yellow-green, tough and blocky cubo-octahedral crystal with predominantly smooth faces of synthetic diamond, used widely for sawing stone. Comparatively, MBS-750 grit has greater toughness and thermal stability than those of MBS- 70 grit. The bond was a mixture of cobalt and bronze. The grit sizes of the diamond were 40/50 and $50 / 60$ US mesh at 20 concentration $\left(0.88 \mathrm{carat} / \mathrm{cm}^{3}\right)$.

\subsection{Sawing tests}

Experiments were performed on a surface grinder, with a variable speed spindle and a variable-speed hydraulic-drive table. The depth of cut was controlled by gear transmission, and could be adjusted to an accuracy of $1 \mu \mathrm{m}$.

\footnotetext{
${ }^{1}$ Trademark of General Electric Company, USA.
} 
All tests were conducted with a reciprocating movement (alternate up-and-down cutting). The sawing tests were carried out under a traverse rate, $V_{w}$ of $1 \mathrm{~m} / \mathrm{min}$ and a depth of cut $a$ of $0.2 \mathrm{~mm}$. Throughout the tests the peripheral blade speed $V_{\mathrm{s}}$ was kept constant at $30 \mathrm{~m} / \mathrm{s}$. The cutting fluid was water. Rectangular blocks of Indian imperial red granite, with approximate dimension of $80 \times 100 \times 150 \mathrm{~mm}$, were selected as workpiece material.

The vertical and horizontal cutting forces during the sawing of granite were measured using a quartz piezoelectric-type dynamometer. The data logger was a data acquisition unit used in conjunction with a personal computer. The force signals for every single revolution of the saw-blade were recorded to provide detailed information.

The radial wear of the saw-blade was measured at three points on the segment by means of a toolmaker's microscope. The reproducibility of measurements could be controlled to under $5 \mu \mathrm{m}$. Blade performance, defined by the ratio of the area of material sawn to the radial wear of the sawblade, was determined to provide an estimate of the mean radial wear over a number of cuts. In addition, worn diamond grains on the working-segment surface were examined and analyzed using a scanning electron microscope (SEM) and a toolmaker's microscope.

\section{Results and discussion}

\subsection{Observation of diamond crystal conditions}

A typical SEM observation of the worn diamond-segment surface of a saw-blade is shown in Fig. 2. The overall distribution and conditions of the diamond particles

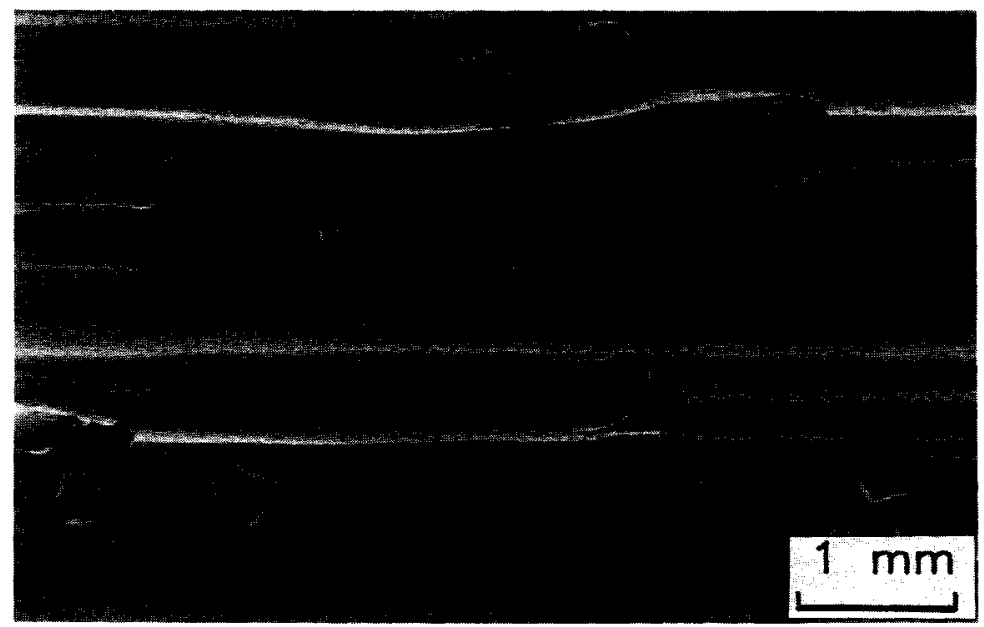

Fig. 2. Showing the surface of a saw-blade. 
on the working surface can be seen. From many observations of the worn surface, the different conditions of the diamond crystal can be classified as follows [11].

1. Whole diamond. This is a particle protruding above the surface of the bond which performs effective cutting work whilst maintaining its crystal shape and displaying no significant surface damage (Fig. 3(a)).

2. Polished (flattened) diamond. These particles (Fig. 3(b)) display a worn area of the smooth or flat faces, under such conditions the blade will be having a glazed appearance. The polished diamond may cause the cutting forces to increase and may, in extreme cases, lead to blade failure. This kind of wear is most probably caused by mechanical attrition.

3. Micro-fractured diamond. These particles (Fig. 3(c)) present micro-cracks, crushed grits, or fragments on the crystal surface and may be a result of the repeated impact or surface fatigue of the workpiece materials. In general, this type of crystal is considered to be a great aid to free cutting.

4. Macro-fractured diamond. This is probably further damage to that of the previous classification of wear. The cutting edges of such particles (Fig. 3(d)) protrude slightly above the surface of the matrix and affect the cutting ability significantly in the extreme case the saw-blade losing its cutting capacity.

5. Diamond pull-out. With the diamond pulled or plucked out of the bond a hole is displayed on the worn surface (Fig. 3(e)). If the diamond is pulled out of the bond before completing its effective working life, the saw-blade will wear very quickly.
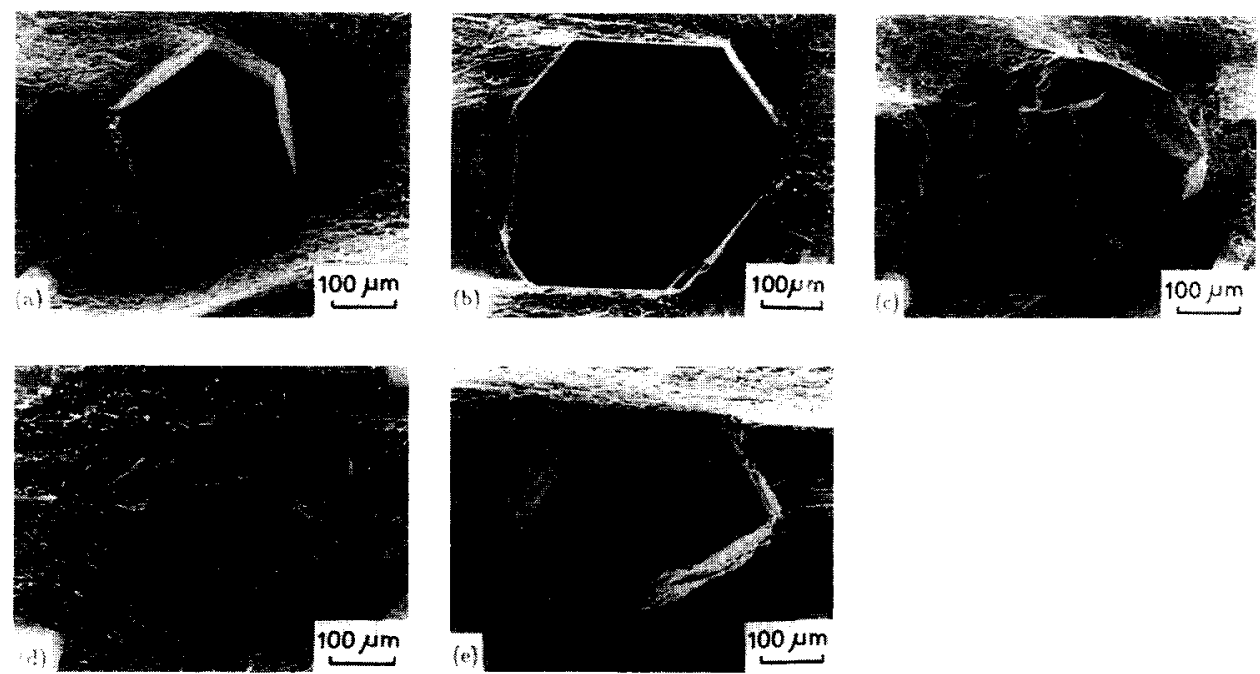

Fig. 3. Micrographs showing the various conditions of worn diamond crystal: (a) whole; (b) polished; (c) micro-fractured; (d) macro-fractured; and (e) pulled-out. 


\subsection{Effects of the diamond type on stone processing}

\subsubsection{Observations of worn grits}

The percentage of each classification (refer to Section 3.1) for the worn diamond after sawing is shown in Fig. 4 for a saw-blade A containing MBS-70 grit of lower toughness and saw-blade B containing MBS-750 diamond of higher toughness. It is found that the percentage of the whole crystal for saw-blade B is $41 \%$, whilst it is only $18 \%$ for saw-blade A. For saw-blade B, there is $20 \%$ of micro-fractured diamond, and only a small amount of polished and macro-fractured diamond. However, the percentage of micro-fractured grit is $38 \%$, and the percentages of the polished and macrofractured diamond are $3 \%$ and $4 \%$, respectively, for saw-blade $\mathrm{A}$. The percentage of the crystal pull-out is similar for these two saw-blades.

From the above results, it is concluded that for the saw-blade containing diamond of greater toughness the predominant proportion of worn grits in the sawing of Indian granite is whole or pulled-out particles whilst for the saw-blade containing grit of lower toughness the resulting crystal conditions appear mainly as micro-fractured and pulled-out grits with a small number of macro-fractured and polished particles on the worn working surface.

\subsubsection{Effects of the diamond type on cutting forces}

The average vertical cutting forces and horizontal cutting forces measured during sawing are shown in Figs. 5(a) and (b) for saw-blade $A$ and saw-blade B, respectively. It can be seen that the horizontal and vertical forces produced for saw-blade $A$ using MBS-70 grit are greater than those for saw-blade B using MBS-750 grit. The ratio of the horizontal force to the vertical force for saw-blades A and B is shown in Fig. 5(c).

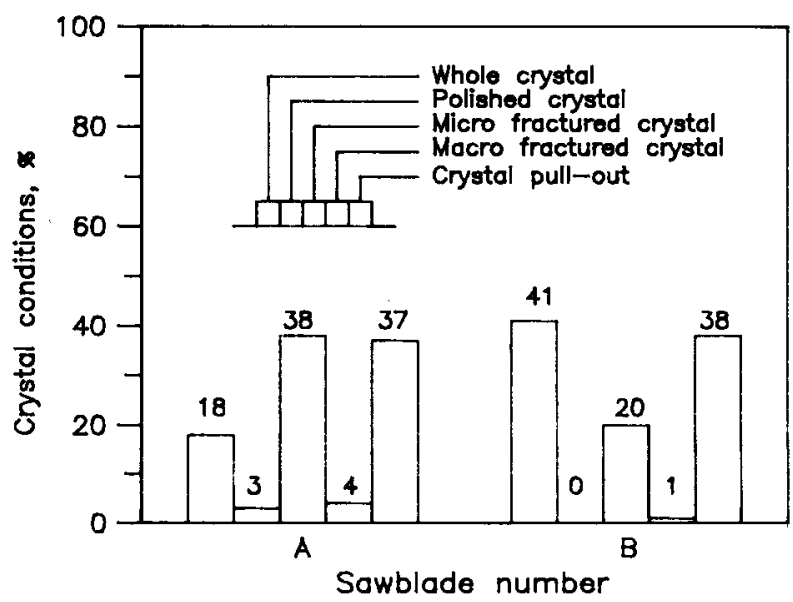

Fig. 4. The percentage of each condition of worn diamond crystal of saw-blades A and B after the sawing of Indian red granite. 


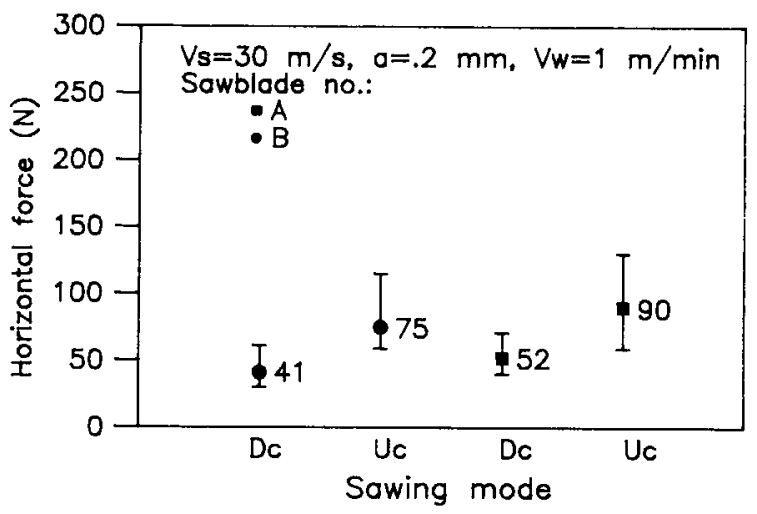

(a)

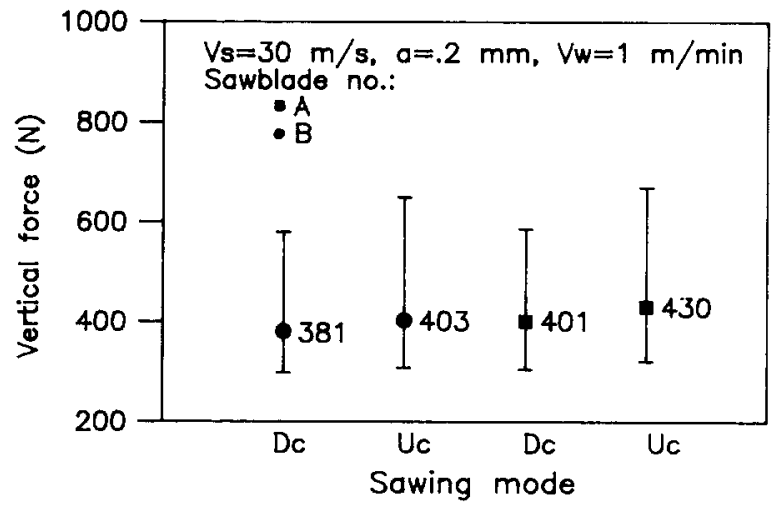

(b)

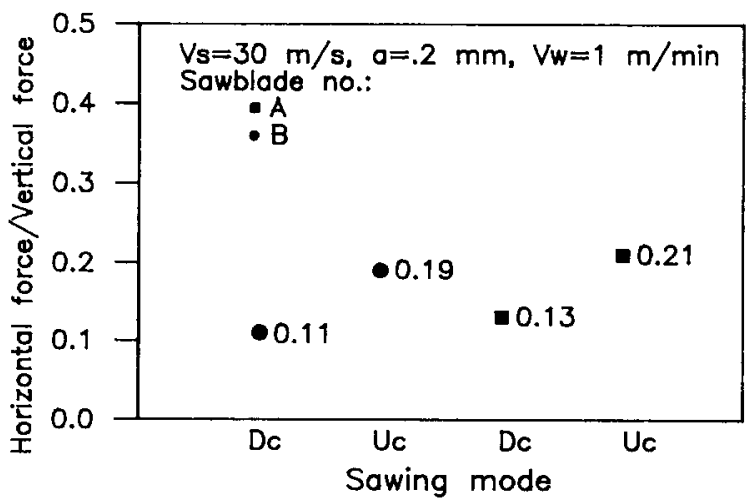

(c)

Fig. 5. Showing: (a) horizontal force; (b) vertical force; and (c) horizontal force/vertical force; when sawing Indian red granite using saw-blades A and B (Dc: down cutting; Uc: up cutting). 
From this figure, it is found that the force ratio for saw-blade A is greater than that for saw-blade B.

Comparing Fig. 5 with Fig. 4, it can be seen that saw-blade A using the lower toughness of grit produces a greater proportion of polished grit or macrofractured particle than does saw-blade B using the higher toughness of grit. Hence, saw-blade $\mathrm{A}$ is caused to produce a higher cutting force during the sawing of red Indian granite.

\subsubsection{Blade performance for two types of diamond grade}

Fig. 6 shows the blade performance of saw-blades A and B. It is found that the blade performance of saw-blade B containing the higher toughness of grit is better than that of saw-blade A containing the lower toughness of grit. This result can also be predicted from the crystal conditions of the worn surface of the saw-blades (see Fig. 4).

\subsection{Effects of the diamond size on stone processing}

\subsubsection{Effects of the grit size on the cutting forces}

The average vertical cutting forces and horizontal cutting forces with $95 \%$ confidence limits measured during sawing in the up-cutting mode or down-cutting mode of the reciprocating movement are shown in Figs. 7 (a) and (b) for saw-blade B containing a larger grit size, and for saw-blade $\mathrm{C}$ containing a smaller grit size. It is seen in Fig. 7 (a) that the horizontal sawing force in up-cutting for a saw-blade $\mathrm{C}$ is greater than that in down-cutting, and its variation is also large. The horizontal cutting force produced in up-cutting and down-cutting for saw-blade B is lower than that for saw-blade C. From Fig. 7(b), it is found that the vertical sawing force in up-cutting for saw-blade $\mathrm{C}$ is greater than that in the down-cutting mode. The vertical sawing forces produced in up-cutting and down-cutting for saw-blade B are lower than those for

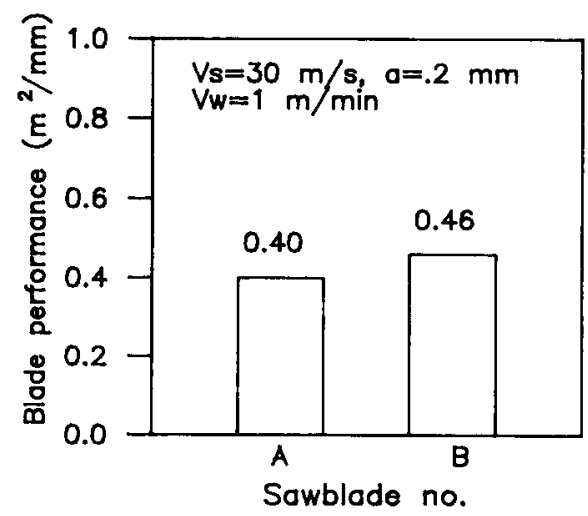

Fig. 6. Blade performance for saw-blades A and B. 


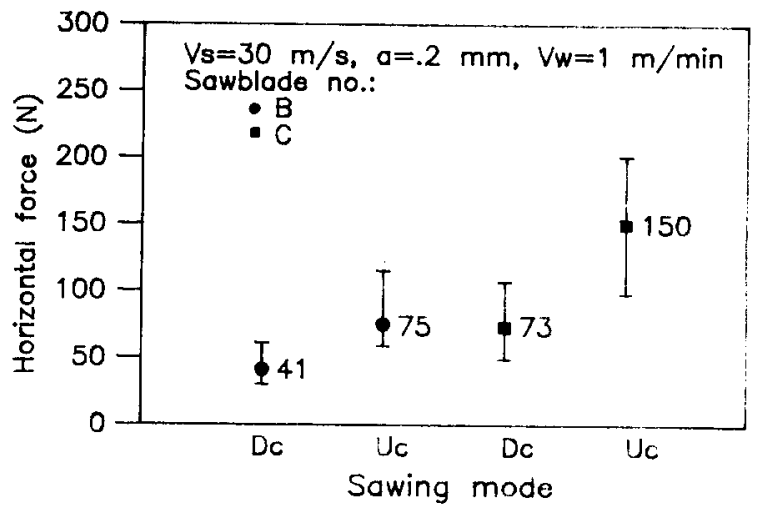

(a)

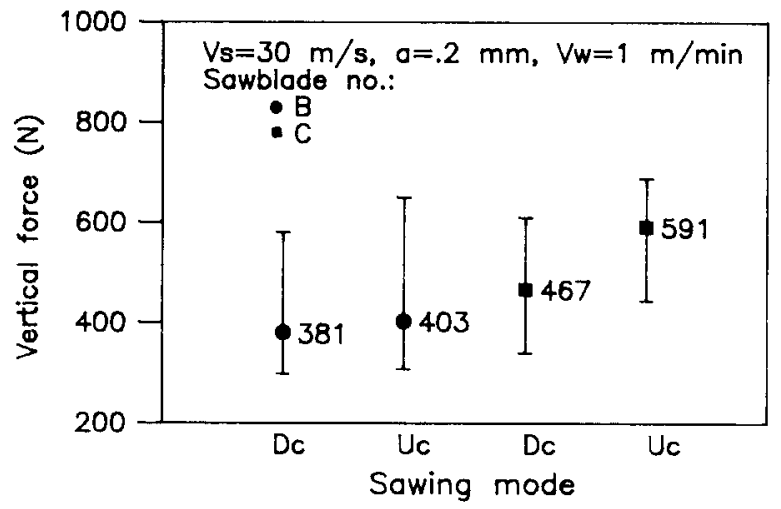

(b)

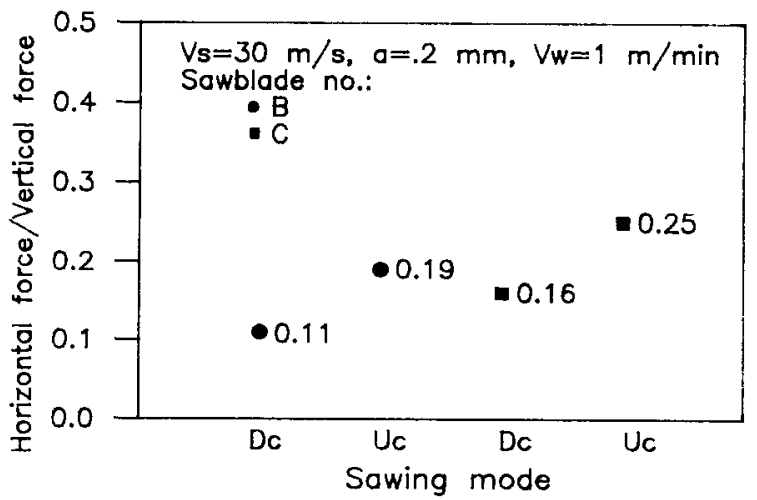

(c)

Fig. 7. Showing: (a) horizontal force; (b) vertical force; and (c) horizontal force/vertical force; when sawing Indian red granite using saw-blades $\mathrm{B}$ and $\mathrm{C}$ (Dc: down cutting; Uc: up cutting). 
saw-blade C. A remarkable difference between the up-cutting mode and the downcutting mode is found in the ratio of the horizontal force to the vertical force, as shown in Fig. 7 (c), the ratio produced for up-cutting being relatively higher than that for down-cutting.

From the above results for the sawing forces, it is implied that when removing the same volume of granite, a saw-blade of smaller size grit has higher cutting forces and force ratio than does a saw-blade of larger size particles. The reason for this is that the chips in the sawing of granite form primarily through a brittle-fracture process by compressive spalling, the crack zone due to indentation for a smaller size grit being smaller than that for a larger grit, so that the material cannot be removed easily by a blade having a smaller diamond size. This in turn causes the cutting forces acting on the blade to increase. Another possible reason is that the working surface of the sawblade using the smaller size grit has a larger number of particles.

When sawing granite in the up-cutting mode, the diamond grit engages the workpiece with a minimal thickness of cut and is thereafter subjected to increasingly loads to reach a critical value, which in turn causes the spalling of the material to be removed. In down cutting, the process starts with the maximum chip thickness, the diamond particles therefore being subjected initially to an impact pulse, causing the stone to spall and be removed. Due to the chip-formation mechanisms of the different cutting modes, it is found in the tests that the cutting forces and the force ratio produced in up cutting are greater than those in down cutting.

\subsubsection{Observations of worn diamond particles}

The worn diamond particles of various classifications were counted, the percentage variations of each classification plotted against the material sawn area for saw-blades $\mathrm{B}$ and $\mathrm{C}$ being given in Figs. 8 (a) and (b), respectively. It is found that for saw-blade $\mathrm{B}$ containing the larger size of grits, there is very small percentage of the polished and macro-fractured diamond, the proportion of the micro-fractured diamond decreasing with the increase of the amount of granite sawn, and the amount of the whole crystal and diamond pulled-out maintaining a relatively higher proportion. For saw-blade C containing the smaller size of grits, the proportion of the crystal pulled-out increases and the percentage of whole diamond decreases with increase of area of stone sawn. The amount of micro-fractured grit maintains a quasi-constant value, and the proportion of macro-fractured and polished crystal is small.

From the results of Figs. 7 and 8, the following summaries can be made.

1. The worn segment surface of the diamond sawblade using the smaller grit size displays a greater proportion of pulled-out crystal. The reason why this occurred is that the volume of the diamond buried in the bond for the smaller size grit is small, so that the bonding strength between the diamond and the matrix is weak, and the diamond is caused to dislodge easily from its bond.

2. When a saw-blade using the smaller grit size is subjected to lower cutting forces acting on the diamond point, the cutting edge of the diamond particle becomes progressively rounded and polished: the cutting forces acting on the blade will then increase under these conditions (see Figs. 8 (b) and 7 (b)). 


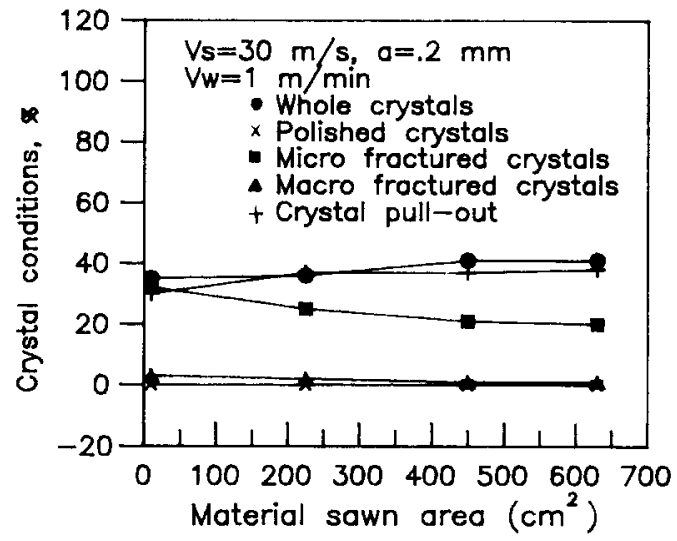

(a)

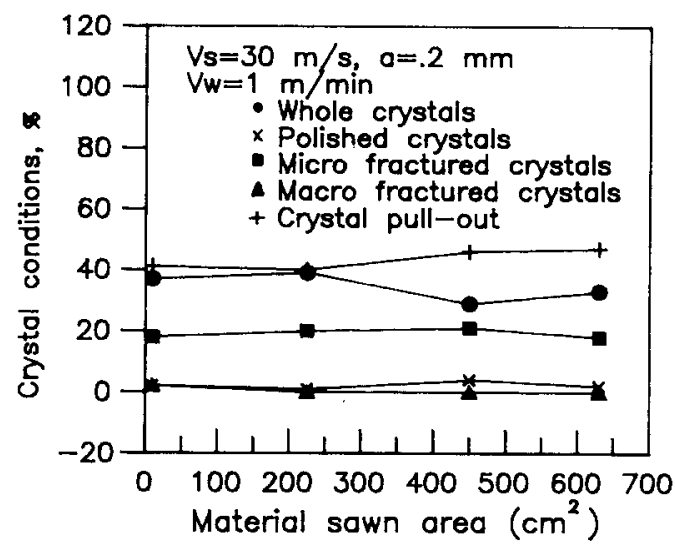

(b)

Fig. 8. Variation of the various classifications of worn diamond crystals with the area of material sawn for: (a) saw-blade B; and (b) saw-blade C.

3. A diamond saw-blade having the larger size grit exhibits a higher proportion of whole crystal and has only a small amount of polished diamond. Hence, the blade has relatively lower cutting forces and is free cutting (see Figs. 8(a), 7(a) and (b)).

\subsubsection{Blade performance for two types of diamond size}

The blade performance of saw-blades $B$ and $C$ is shown in Fig. 9, from which figure it is seen that the blade performance of saw-blade C containing the smaller size grit is better than that of saw-blade B having the larger size grit, the reason for this possibly being attributable to the larger number of grits on the working surface of saw-blade $\mathrm{C}$. 


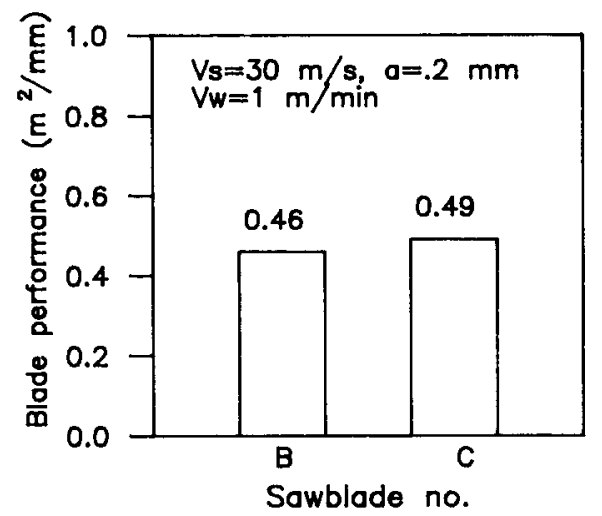

Fig. 9. Blade performance for saw-blades B and C.

\section{Conclusions}

Based on the results of this investigation, the following conclusions can be drawn.

1. The crystal conditions of the working surface of the saw-blade for stone processing can be classified as whole (without significant wear), polished (flattened), microfractured, macro-fractured, and pulled-out.

2. When a saw-blade containing the greater-toughness grade of diamond particle is used in the sawing of Indian red granite, the resulting crystal conditions occur mainly as whole and pulled-out grits, whilst the number of polished and macro-fractured grits is very small. This produces a relatively lower sawing force, and the saw-blade displays a better blade performance. Conversely, a saw-blade containing the lower toughness of grits displays predominantly micro-fractured and pulled-out particles with a small number of polished or macro-fractured grits on the worn working surface, greater sawing forces, and a poorer blade performance.

3. A saw-blade containing the smaller grit size at constant concentration during sawing exhibits a better blade performance. However, the sawing forces are relatively higher, there is a greater proportion of pulled-out crystal and a small number of polished grits occurs on the worn surface. When a tool is made up of larger size particles, the sawing forces are characteristically lower, and a predominant proportion of whole grit with a very small number of polished or macro-fractured particles appears on the working surface. However, the blade performance is poorer.

\section{Acknowledgements}

This work was supported by the Taiwan Diamond Industrial Company Ltd. and the General Electric Company. The authors are especially grateful to Dr. C.C. Chou, General Manager, and Mr. C.L. Chen, Manager, for their help and advice. 


\section{References}

[1] M. Jennings and D. Wright, Guidelines for sawing stone, Ind. diamond Rev., 49 (2) (1989) 70-75.

[2] A. Büttner, Diamond tools and stone, Ind. Diamond Rev., 34 (1974) 89-93.

[3] H.K. Tönshoff and G. Warnecke, Research on stone sawing, in: P. Daniel (ed.), Advances in Ultrahard Materials Application Technology, Vol. 1, Hornbeam, England, 1982, pp. 36-49.

[4] R.R. Burgess, Man-made diamond for stone processing, GE Publication No. SMD 89-329.

[5] M.W. Bailey and G.J. Bullen, Sawing in the stone and civil engineering industries, Ind. Diamond Rev.. 39 (1979) $56-60$.

[6] D.N. Wright and V.B. Cassapi, Factors influencing stone sawability, Ind. Diamond Rew., 45(2) (1985) 8487 .

[7] D.N. Wright and H. Wapler, Investigations and prediction of diamond wear when sawing, Ann. CIRP, 35(1) (1986) 239-244.

[8] W. Ertingshausen, Wear processes in sawing hard stone, Ind. Diamond Rev., 45 (5) (1985) 254 258.

[9] A.G. Mamanlis, R. Schulze, and H.K. Tönshoff, The slotting of blocks of hard rock with a diamond segmented circular sawblade, Ind. Diamond Rev., 39 (1979) 356 365.

[10] S.Y. Luo and Y.S. Liao, Effects of diamond grain characteristics on sawblade wear, Int. J. Mach. Tools Manufact., 33(2) (1993) 257-266.

[11] Y.S. Liao and S.Y. Luo, Wear characteristics of sintered diamond composite during circular sawing, Wear, 157 (1992) 325-337. 